10.31341/jios.45.2.7

UDC 004.946:37

OOpen Access

Survey Paper

\title{
Use of Augmented Reality with Game Elements in Education - Literature Review
}

\author{
Tamara Ređep \\ Faculty of Organization and Informatics \\ University of Zagreb, Varaždin, Croatia \\ Goran Hajdin \\ Faculty of Organization and Informatics \\ University of Zagreb, Varaždin, Croatia
}

tamredjep@foi.hr

goran.hajdin@foi.hr

\begin{abstract}
This paper reviews the literature and analyzes the research topics on the use of augmented reality technology in education with possible integration of game elements, in order to obtain a synthesis of previous knowledge related to the topic in the period from 2010 to 2020 . Fifty-two papers describing different aspects of augmented reality used in the field of education were selected for the analysis. The main conclusions of the systematization and synthesis were: a) five basic thematic categories were identified; b) 2019 was recognized as the year with the largest publication of papers; c) the use of augmented reality in teaching activities, and especially with game elements, improves student efficiency, stimulates attention and interest, brings improvements in collaboration and perception of fun, improves teaching and learning processes and in general encourages innovation and improvement through educational technology.

Keywords: augmented reality, education, learning, game, school, formative
\end{abstract} assessment

\section{Introduction}

In order to modernize the teaching process, teachers apply the educational trends that put students in an active relationship with the content of learning and encourage independence and responsibility for learning. Information and communications technology (ICT) provides many opportunities that can be used in the process of teaching and learning [1], so today it is almost impossible to imagine formal and nonformal education without the use of computers and new technologies that bring teachers a range of new tools, and provide a new and innovative approaches to teaching [2]. Therefore, new technologies such as augmented reality (AR) and Digital game technology (DGT) are considered to have great potential for education [3].

AR is combining the physical and virtual worlds, offering unique display capabilities for the user with a combination of the actual scene the user is watching and computer-generated virtual scenes. It is an interactive environment in which 
reality is enhanced by real-time virtual objects [4]. According to [5] AR must have three characteristics and properties: 1) Combines real and virtual objects in a real environment, 2) Runs interactively, and in real time, and 3) Registers and aligns real and virtual objects with each other.

When DGT is mentioned, two concepts are meant: Game-based learning (GBL) and gamification. Gamification is defined as the application of digital game mechanics in a non-gaming context for the purpose of engaging students, motivating activities, improving learning, and problem solving [3]. The concept of gamification is sometimes mistakenly equated with the concept of GBL, which is actually a supplement to classical teaching through the application of technology and games for the purpose of acquiring knowledge and skills, and in this case it is most often educational video games [6]. Thus gamification tries to make a game out of the learning process, while GBL includes the game as part of the learning process [3].

Although this new approach involving the use of AR with digital game technology certainly increases the efficiency and attractiveness of teaching and learning, in order to gain a detailed insight into their application in education, a literature review was conducted. We analyzed which areas are using AR technology with game elements and what are the results of its usage, but also which year, in the period from 2010 to 2020 , is the greatest interest in this topic given the number of papers. The analysis of previously researched topics will result in a synthesis of previous knowledge on the use of AR with game elements in education.

This is also the primary goal of the research, and based on it, we defined three research questions:

Q1: What thematic categories can be identified in the analyzed papers?

Q2: What is the representation of the papers in a certain thematic category considering the year of publication?

Q3: What common conclusions can be drawn from the synthesis of papers obtained by analysis in each thematic category?

\section{Methodology}

The research methodology was conducted following the steps proposed by J. W. Creswell [7].

1. Identifying keywords. In the first step we defined the basic keyword phrase "augmented reality", which was searched in combination with the keywords: education, mobile, game, learning and school. Since Creswell [7] proposes to select about 50 papers, the combination of keywords depended on the search result, and the number of papers obtained. If the number of papers as a result of the search have been too large, additional keyword phrase "formative assessment" has been included in the search.

2. Search the scientific databases. The search was performed in the Web of Science Core Collection (WoSCC) and Scopus databases, as they contain the scientific papers of the first group (a1) ${ }^{1}$ in the field of social sciences according to

1 Regulation book on the conditions for election to scientific titles 
the Croatian legislation that is relevant to the field of research. WoSCC is a multidisciplinary bibliographic and citation database available through the Web of Science (WoS) research platform, and Scopus is the world's largest bibliographic and citation database that includes European journalism, especially in the social sciences and humanities [8]. The search also included a free scientific literature search engine Google Scholar, and Hrčak - Portal of scientific journals of the Republic of Croatia in order to search the literature in the Croatian language [9].

3. Defining papers related to the research topic. As the field of using AR in education is changing very quickly, an additional criterion for searching databases within a time period in the last 10 years has been included in the search. The search began by entering the basic keyword phrase "augmented reality", and adding keywords education, mobile, game, learning and school in the exact order as stated. The initial search according to the previously mentioned keywords and time criteria resulted in an excessive number of papers in the Scopus database (964 papers) and the Google Scholar search engine (18,000 papers) in relation to the set goal of about 50 papers. Therefore, the additional search criteria was included in the Scopus database: Computer Science and Social Science were singled out as the areas of research, as a type of document an Article and a Conference Paper were selected, English was chosen as a language, and also an additional keyword phrase "formative assessment" was included. Although all the keywords were entered in the Google Scholar search engine as in the Scopus database, the result was still too large for analysis $(3,380$ papers), so the search was narrowed down to the term augmented reality in a different combination with keywords, but in the titles of the papers. First, the keywords education and game were added to the keyword phrase "augmented reality". Then a new search was performed, in which the keywords game and learning were added again to the keyword phrase "augmented reality". And in the last search, the keywords phrase "formative assessment" also was added to the keyword phrase "augmented reality". The obtained results in all three previously mentioned research steps were taken into the analysis. Since the initial search of the Hrčak database just with the keyword phrase "augmented reality" and keyword education resulted in 4 papers, no additional keywords were introduced into the search.

4. Selection of papers relevant to the research topic. In order to select papers relevant to the research topic, some papers have been eliminated. Those are papers dealing with the technical aspects of AR, those related to the use of AR in some activities, e.g. in tourism and health, those that consider the impact of AR on only a certain group of users, most often with some developmental difficulties, those that do not have concrete research results and those papers that appear in several databases.

5. Creating a literature map - a visual image of grouping literature. The papers selected for analysis are presented in a table instead of a literature map for clarity and are grouped according to the established thematic structure. The categorization of the use of AR in the field of education depending on the level of education was also included in the review, in order to investigate the possible difference depending on whether it is primary, secondary or tertiary educational level.

https://narodne-novine.nn.hr/clanci/sluzbeni/full/2017_03_28_652.html 
6. Analysis of selected papers. Based on the thematic grouping, an analysis of the selected papers was performed to determine their common conclusions.

7. Summary creation and final literature review. The last step of the research is the final review of the literature, which is organized according to the identified important concepts, and is obtained by synthesizing all the relevant conclusions of the selected papers.

\section{Research results}

Considering the previously defined keywords and search criteria for individual databases described in the previous chapter in the part "Defining papers related to the research topic", the results are 39 papers from the WoSCC database, 29 papers from the Scopus database, 103 papers from the Google Scholar search engine, and 4 papers from the Hrcak database. These results are shown in Table 1.

\begin{tabular}{|l|c|c|c|c|}
\hline $\begin{array}{l}\text { Search criteria - keyword } \\
\text { phrase AR + keywords: }\end{array}$ & WoSCC & Scopus & $\begin{array}{c}\text { Google } \\
\text { Scholar }\end{array}$ & Hrčak \\
\hline +education & 1,883 & 6,753 & 119,000 & $\mathbf{4}$ \\
\hline +mobile & 553 & 3,977 & 54,100 & \\
\hline +game & 113 & 1,933 & 21,300 & \\
\hline +learning & 85 & 1,677 & 18,300 & \\
\hline +school & $\mathbf{3 9}$ & 964 & 18,000 & \\
\hline +formative assessment & & $\mathbf{2 9}$ & 3,380 & \\
\hline $\begin{array}{l}\text { In the titles of the papers: } \\
\text { a) AR + education + game } \\
\text { b) AR + game + learning } \\
\text { c) AR + formative assessment }\end{array}$ & & & $25+$ & \\
\hline
\end{tabular}

Table 1. Database search flow and obtained results

Having selected out the papers relevant to the research topic, the final results are 52 papers describing different aspects of the AR usage in the field of education, the initial analysis of which identified five basic thematic categories. Thus we distinguish I) papers that provide an overview of the literature related to the use of AR in education, II) those that deal with its impact on the effectiveness, motivation and achievement of students with or without game elements, III) those that focus on designing and testing learning application based on AR and games elements, IV) those that examined the impact of applications based on AR on formative assessment, and V) those that consider the interests and attitudes of professors, students and faculty on the use of $\mathrm{AR}$ in education. This division is also the answer to the first research question.

Their mutual relationship with regard to such an established thematic structure is shown in Table 2. In the category describing the impact of AR on the effectiveness, motivation and achievement of students with or without the use of game elements, a division was made according to the level of education, where 1 is primary, 2 is secondary, and 3 is tertiary educational level. Along with each thematic division, the 
authors dealing with that topic are listed in a separate column under the reference number.

\begin{tabular}{|c|c|c|}
\hline \multicolumn{2}{|c|}{$\begin{array}{r}\text { Thematic category } \\
\end{array}$} & Year [Reference] \\
\hline \multicolumn{2}{|c|}{$\begin{array}{l}\text { The review of the literature on the use of } \\
\text { AR in education }\end{array}$} & $\begin{array}{l}2016 \text { [10], } 2016 \text { [11], } 2017 \text { [13], } \\
2018 \text { [12], } 2019 \text { [14] }\end{array}$ \\
\hline \multirow{3}{*}{$\begin{array}{l}\text { The impact of AR } \\
\text { on the } \\
\text { effectiveness, } \\
\text { motivation and } \\
\text { students } \\
\text { achievements with } \\
\text { or without game } \\
\text { elements }\end{array}$} & Educational level 1 & $\begin{array}{l}2014 \text { [18], } 2016 \text { [16], } 2016 \text { [19], } \\
2017 \text { [15], } 2018 \text { [20], } 2018 \text { [21], } \\
2018[23], 2019 \text { [22], } 2019[24], \\
2020[17]\end{array}$ \\
\hline & Educational level 2 & $\begin{array}{l}2010[25], 2013 \text { [32], } 2014 \text { [26], } \\
2015[27], 2015[28], 2015 \text { [29], } \\
2017[30], 2018[31]\end{array}$ \\
\hline & Educational level 3 & $\begin{array}{l}2016[35], 2018 \text { [37], } 2019 \text { [33], } \\
2019[34], 2020 \text { [36] }\end{array}$ \\
\hline \multicolumn{2}{|c|}{$\begin{array}{l}\text { Designing and testing learning } \\
\text { applications based on AR and games } \\
\text { elements }\end{array}$} & $\begin{array}{l}2013 \text { [38], } 2013 \text { [41], } 2016 \text { [42], } \\
2016[51], 2017 \text { [39], } 2017 \text { [40], } \\
2017[43], 2017[46], 2017 \text { [47], } \\
2018[50], 2019 \text { [44], } 2019 \text { [48], } \\
2019[49], 2019 \text { [53], } 2020[45], \\
2020[52]\end{array}$ \\
\hline \multicolumn{2}{|c|}{$\begin{array}{l}\text { Formative assessment using an } \\
\text { application based on AR }\end{array}$} & $\begin{array}{l}2014 \text { [56], } 2018 \text { [54], } 2019 \text { [57], } \\
2020[55]\end{array}$ \\
\hline \multicolumn{2}{|c|}{$\begin{array}{l}\text { Interests and attitudes of professors, } \\
\text { students and faculty on the use of AR in } \\
\text { education }\end{array}$} & $\begin{array}{l}2017[58], 2019[59], 2019[61] \\
2020[60]\end{array}$ \\
\hline
\end{tabular}

Table 2. Thematic structure and division of selected papers

Table 2 shows that the largest number of papers is classified in the category that deals with the designing and testing learning applications based on the elements of AR and games. This is followed by a category in which the impact of AR on the effectiveness, motivation and achievement of students with or without game elements is examined, mostly in the first level of education, while a smaller number of papers are distributed in the other categories.

Observing Figure 1 and the distribution of selected papers in each thematic category according to the year of publication in the paper reference, we can conclude that the number of papers dealing with AR and game elements in education has increased in the last 5 years. From 2010 to 2015, only 10 papers were published, while from 2016 to 2020, the number of published papers was 42. The largest number of analyzed papers was published in 2019, which means that the publication of papers has decreased in the last year. At the same time, we can see that in all categories there is a tendency to increase the publication of papers after 2015, except in the category of examining the impact of AR on the effectiveness, motivation and achievement of 
students with or without game elements at the Educational level 2. The results of this analysis are the answer to the second research question.



Figure 1. Graphic presentation of the papers distribution from thematic categories by years

\subsection{Analysis, review and synthesis of papers according to the established thematic classification}

Based on the presented thematic grouping of selected papers, the following is their analysis, review and synthesis in order to identify and single out commonly important conclusions. In each thematic group, the papers are grouped according to whether they apply only AR or use some game elements in addition to AR, but also according to similar concepts of research.

\subsubsection{The review of the literature on the use of $A R$ in education}

Analyzing the use of AR in science education in papers published between 2006 and 2016, Swensen [10] identified four key factors that may directly or indirectly have a 
positive effect on learning outcomes in science: cognitive effort, motivation, situated learning and inquiry based learning.

Lin i Tsai [11] in the analysis of papers conducted in Taiwan during the period 2003 - 2012 related not only to the use of AR technology, but also to the use of other innovative technologies such as mobile and game-based learning. The paper shows trends and successful experiences of Taiwanese teachers in the field of technological learning in science education. In the papers published in the period from 2012 to 2017 , in addition to AR, we also find the use of game elements. Thus, Laine [12] in the results of his systematic literature review indicates that EMARGs have been used around the world for various pedagogical purposes in a variety of ways. The paper results by Fotaris, Pellas, Kazanidis and Smith [13] indicated that AR with GameBased Learning (ARGBL) applications are mainly used to document the design and development process, as well as to share preliminary findings and student feedback. The findings of this paper are also that ARGBL can positively affect students' attendance, knowledge transfer, skill acquisition, hands-on digital experience, and positive attitudes in laboratory experimental exercises for different courses. This group of authors was joined by Wells [14] in the analysis of ARGBL, related to the review of new trends and experiences. These researchers have taken notice that the published papers about ARGBL, particularly in primary education, have significantly increased in the last couple of years. They also find that ARGBL was mostly applied in STEM subjects, and that motivation and enrichment of the learning experience when using ARGBL, can lead to clear enjoyment, knowledge gain, augmented interaction, increased engagement, and enhanced collaboration.

In this category different authors analyze various aspects of the usage of AR in education. It can be concluded that the number of published papers related to EMARG and ARGBL in primary and secondary education is gradually increasing as well as the number of teachers using them for various pedagogical purposes. Also, AR generally has a positive effect on students' attitudes, motivation and therefore on learning experience.

\subsubsection{The impact of AR on the effectiveness, motivation and students achievements with or without game elements}

\section{a) Educational level 1}

The results of an experiment conducted by Chien-Hsu, Chun-Yen i Yin-Yu [15] related to the understanding of growth pattern of the leaves, showed that students enjoyed the learning activities with the AR-based Blended Learning (ARBL) approach and that they were interested in the learning course. Solak and Cakir [16] have investigated the effectiveness of the AR application in a language classroom. They concluded that the AR application increases academic performance of learners and helps store new vocabulary items in memory longer than with the use of traditional methods. Chih-Hung [17] comes to similar results, with the designed AR video-enhanced learning (ARVEL) method to assist students' learning English as a foreign language (EFL). The results show that the ARVEL method significantly 
improved students' learning achievements and their intrinsic motivation and satisfaction, compared to the students learning in a conventional video-based way.

In addition to AR technology, the integration of ubiquitous games is common. Leitão, Rodrigues and Marcos [18] in their paper presented the development of a game in a teaching and learning context, aiming to help students acquire knowledge in the field of geometry. The authors showed that by using the game students have improved around $35 \%$ the hits of correct responses to the classification and differentiation in 3D solids. Young, Kristanda and Hansun [19] also wanted to create visualization effects with an application which can attract more attention from learners in geometry. The implementation of AR has been shown to improve students' motivation to learn, and students prefer to use AR in this game. To help students learn maths, Pritami and Muhimmah [20] explored the development of a Digital Game Based Learning application using AR for learning mathematics. The purpose of this application is to sharpen counting ability as well as to train children's motor nerves so they can become more active, and the result is that students claimed to be glad and enthusiastic to learn maths using this game. For learning English Chen, Hung, Chang, Lin and Lai [21] in their paper focus on development of a GBL system with the AR technology. Through the interactions of voice, graphics and real-world environments, students can learn the common vocabulary of each English letter. The results showed that this way of learning is significant in improving students' motivation and effectiveness. Also for learning English language, Hao and Lee [22] developed four AR games by integrating theories of digital game-based learning, the attention relevance confidencesatisfaction (ARCS) model, and different types of digital games. The results showed that students who used AR games in learning were significantly higher motivated to learn than students who learned in the traditional way, but no significant differences in their learning effectiveness were observed. The finding of this study is also that $3 \mathrm{D}$ graphics is the most important element in the design of AR games, and the most popular type of AR game is role-playing. Herpich, Nunes, De Lima and Tarouco [23] in their paper presented an orientation activity, combined with the use of technological accessories like AR in the teaching-learning process of Geography, that not only contributed to the visualization of the content but also to establishing the relationship between theory and practice. All these previous conclusions are confirmed by the results of research presented by Sáez-López, Sevillano-García and Pascual-Sevillano [24] in Art Education. They showed that the experimental group achieved statistically significant improvements in academic subject performance, motivation, information retrieval and analysis, level of entertainment, and collaboration.

The analysis of published papers shows that the use of AR, and especially with the game elements, has a positive impact on student motivation and satisfaction, improves their efficiency, stimulates attention and interest, brings improvements in collaboration and perception of fun, and often in student achievements in the learning area in which the research was performed. 


\section{b) Educational level 2}

In their paper Spikol and Eliasson [25] reported on the findings from a mobile geometry project pilot designed together with teachers. The project consisted of outdoors and indoors activities with an aim that combines mobile and 3D technologies that allow students to collaboratively explore and discuss geometrical concepts. The results showed that teachers believed that the learning goals have been met, but all have mentioned the impracticability of this activity in everyday practice, as well as that they have expected greater ease of the technology usage. Students find this aspect of learning a good way to experience maths even with technical problems. Of the analyzed papers, the most research is focused on teaching chemistry. One of them is from the authors Cai, Wang and Chiang [26] in which students were able to use markers to control, combine, and interact with a 3D model of micro-particles and conduct a series of inquiry-based experiments. By analyzing the data, they concluded that AR has a significant effect as a computer-assisted learning tool, that AR tool is more effective for low-achievement students, and that students' attitudes toward learning are positively correlated with their evaluation of software. Boonterng and Srisawasdi [27] also presented a chemistry teaching strategy as learning with AR, where an AR-oriented model-based inquiry learning environment can improve the way students learn chemistry and engage them to criticize and think meaningfully about natural phenomena. They also found that there is no significant difference between genders in fostering their perceptions to learn chemistry with the mobile AR. The attitude towards chemistry with regard to gender is also examined by Kumta and Srisawasdi [28]. Their results showed that there is no significant correlation between attitudes towards chemistry and perception towards the AR. There was also no significant correlation between the genders and their perception toward the AR. The same results were reached by Sakulphon, Srisawasdi and Preeya [29] by examining attitudes toward the mobile AR with respect to gender but in biology. The results of their paper showed that student perception toward AR technology was not defined by their attitudes toward biology, and disparity of gender did not affect their perception toward learning with mobile AR.

If we include the use of educational games in addition to AR technology, then the results of research conducted by Hou and Lin [30] show that students significantly improved their learning after playing an educational game on a mobile device combining AR and a virtual laboratory for chemistry experiment learning. Meekaew and Ketpichainarong [31] compared the results of using mobile game-based learning (MG) and mobile game-based learning integrated with AR (MGAR) on understanding biodiversity and motivation to learn in the museum. The result showed that MGAR had a greater impact on improving students' understanding of biodiversity and provided more motivation than MG significantly. Salazar, Gaviria, Laorden and Bringas [32] also presented a game in their paper, but that serious game was designed to enhance an information security presentation. This was achieved through the use of AR to shape intangible cybersecurity concepts and allow the students to interact with them. The results showed that this serious game is a valid learning tool that helps 
to consolidate information security concepts, by making them "tangible" to the users and providing them an interactive context for experimentation.

In papers dealing with the use of AR in secondary educational level, the results show that despite the possible technical problems of applying AR as a computerassisted learning tool, learning objectives are met and students regardless of gender positively perceive the learning experience in this way. With the inclusion of game elements, students significantly improved their learning, but also their activity through collaboration with other students.

\section{c) Educational level 3}

In his paper Lee [33] comes to the conclusion that AR training has helped students to improve their 3D visualization, and also to improve their understanding of carpentry skills and of the complicated mortise-tenon joint structure. Chin, Wang and Chen [34] stated that AR finds its effective usage beyond traditional classrooms. They designed an AR-based mobile learning system to teach a liberal arts course at a Taiwanese university. This system helped students to engage in authentic learning activities independently without direct teacher assistance, and it provided an opportunity for teachers to improve on the effectiveness of conventional outdoor instructional approaches.

The potential of the location-based AR game on engagement and enhancing learning experience for advanced level EFL learners, is confirmed by the results of research presented by Richardson [35]. Also for EFL learning, Lee [36] in his paper compared the effects of an AR mobile game and a printed game on student engagement and attitudes, and the data obtained show that students may sustain high levels of engagement and positive attitudes regardless of the medium (AR technology versus print). But, although $\mathrm{AR}$ technologies provided authentic and immersive learning environments, EFL students perceived print reading as more useful for learning English than digital reading. Kazanidis, Tsinakos and Lytridis [37] examined the potential of using a game-based AR mobile application to teach mobile programming, and the first students' feedback about the application was very positive. They considered application as a useful and fun tool for their study.

By analyzing these papers, it can be concluded that AR is applied mostly in vocational subjects where it is important to achieve improved visualization. But greater motivation to learn, better learning outcomes and the ability to understand were also achieved. In combination with games, AR is used for the purpose of engaging students and improving the learning experience.

\subsubsection{Designing and testing learning applications based on elements of AR and games}

Ferrer, Perdomo, Rashed-Ali, Fies and Quarles [38] developed and evaluated an application of mobile phone AR for passive solar energy education (AR-SEE). Their findings are: a one-marker design with a touchscreen interface may have a usability advantage over a touchscreen-tangible hybrid design for AR serious games, in some 
cases, a one-marker AR design may have increased learning benefits over a multimarker design, and despite decreased usability, AR serious games can enhance motivation to learn over desktop interfaces. The same authors [39] extended their existing educational simulation AR-SEE to include virtual human inhabitants. The results showed that virtual human visualization of temperature data enabled higher motivation than the particle visualization for learning in the tangible AR environment. In their paper Alakärppä, Jaakkola, Väyrynen and Häkkilä [40] present a concept, prototype and in-the-wild evaluation of a mobile AR application in which physical items from nature are used as AR markers. Teachers found the use of natural objects to be an appealing approach and a factor contributing to the learning experience.

Ştefan and Moldoveanu [41] have analyzed how game concepts and design principles can be applied or adapted to the AR, and how the AR technology affordances can be leveraged in order to implement a new class of educational and simulation games. They also present a concept of an educational AR game as a teaching and learning tool, which can stimulate students' creativity, competitiveness, social interaction and critical-thinking. But, the integration of curricula in serious games is a difficult task, so they suggested that it can be facilitated if the learners (students) can participate in game development and content production. Tobar, Fabregat and Baldiris [42] agree with that, but instead of cooperating with students, they suggested cooperating with teachers and in their paper they introduce CoCreARGBL as a method for Co-Designing ARGBL learning experiences involving teachers and designers as well. They have found that teachers find the process very useful and feel satisfied with the resulting tools and experiences, and are ready to use them in the classroom. The same authors [43] devised an AR game using a designbased research approach, but with the help of teachers. Their findings are that although there is no difference in results in reading comprehension using the game to results from the more traditional approaches, students do display greater motivation and interest in the activity, and the activity is enriched as it promotes problem solving, exploration, and socialization behavior.

Furthermore, Sudarmilah, Ustia and Bakhtiar [44] in their paper utilize AR Educational Game (AR EduGame) as a learning media that can cognitively stimulate students. The results of the implementation showed that AR EduGame can be considered as a quality and feasible learning media, especially in learning Indonesian culture regarding gamelan and traditional dances. Costa, Manso and Patrício [45] presented a mobile AR platform PlanetarySystem $G O$ which consists of a locationbased game targeted to promote learning about the Universe. Authors concluded that the game promotes students' interest and engagement to play it and to learn about the Solar System, and that this platform may be used as a resource to be implemented in informal and formal learning environments. Learning through outdoor activities Mozelius, Eriksson Bergström and Jaldemark [46] demonstrated in their paper through the usage of the Pokémon Go game in which in order to catch Pokémon figures, players must physically move to where the character is located. The results showed that Pokémon Go can be seen as a learning-stimulating game that could augment traditional teaching sessions in formal education. Students reported that they enjoyed catching the Pokémon figures the most, and some students also mentioned 
that they appreciated the maths assignments. But, the most positive findings were that there were concrete learning outcomes and that this mobile game encourages students to engage in collaborative learning.

Very often, the papers mention the game EduPark, which is designed for outdoor learning settings by applying the principles of geocaching ${ }^{2}$ and $A R$ mobile technologies. The aim of the game is to develop authentic learning on various interdisciplinary topics in a smart urban park. Pombo, Marques, Lucas, Carlos, Loureiro and Guerra [47] presented the game prototype development. The evaluation allowed identifying positive characteristics of the game, such as immediate feedback and collaborative dynamics, but some questions included in the learning guides were perceived as difficult to understand. Two authors from this group, Pombo and Marques [48] in their paper are focused particularly on data of participants attending the first four years of primary education. The results showed that the EduPARK game achieved good usability and has educational value for primary education students. The same authors [49] in a new study using the EduPARK game as well, analyzed mobile learning through students' opinion regarding the use of mobile devices for learning, as well as the educational value of a specific mobile learning strategy. The results showed that most students owned a mobile device and were able to use them to learn. They had a positive perspective regarding mobile learning, they valued the advantages of being easy to find up-to-date information, and easy to carry mobile devices. But there were some difficulties, and they are related to the use of mobile devices, such as requiring an internet connection, its slowness and prohibition of mobile devices in schools.

In order to assess the effects of combining ARGBL and a multiplayer approach, the authors Ortiz, Vitery, González and Tobar-Muñoz [50] built an ARGBL multiplayer video game where learning takes place indirectly, motivated by the use of components such as AR and social interaction. They concluded that competition integrated in the game allowed students to learn the educational content in a fun way as they looked to get advantage over their opponent, however some students still preferred to play in a collaborative way. Teachers emphasized that the use of that game supports learning by association, provides a fun experience that captures students' attention and increases their motivation. Hwang, Wu, Chen and Tu [51] proposed a competitive gaming approach to support AR-based learning activities conducted in a real-world context. The results showed that the AR-based gaming approach can improve not only students' learning attitudes, but also their learning performance. To assess the usability of the two game styles competitively and collaboratively, and their impact on user communication and motivation. LópezFaican and Jaen [52] tested the mobile AR game EmoFindAR. They concluded that both ways of playing are satisfactory for students and trigger positive emotions such as enthusiasm, pleasure and curiosity that improve participants' mood and help increase the degree of involvement. But they noted that the collaborative game version has a greater impact on emotional affection, social interaction and interest. Based on

\footnotetext{
${ }^{2}$ Cambridge dictionary: the activity of using GPS to search for small hidden prizes https://dictionary.cambridge.org/dictionary/english/geocaching
} 
these findings, Bressler, Bodzin, and Tutwiler [53] examined whether player's flow experience differed by achievement track, gender, or gender composition of working groups in a collaborative mobile game. The paper found that gender was related to flow experience, and specifically girls reported higher flow experience scores. But, flow experience did not have a statistically significant relationship with achievement track showing that the activity engaged all observed students similarly.

The results of the analyzed papers show that an AR game based approach can improve not only students' learning attitudes, but also their learning performance. Both styles of play, competitive and collaborative, encourage positive emotions such as enthusiasm, enjoyment, and curiosity that improve participants' moods and help increase the degree of involvement. But some students prefer to play as a team, and playing together has a greater impact on emotional affection, social interaction, and student interest. Also, designers are not always aware of the specifics of learning or curriculum design, and teachers lack expertise and time, so a method to jointly create an ARGBL learning experience has been proposed. The results of the evaluation of the analyzed applications show that they all have educational value, have positive characteristics of the game such as current feedback and dynamics of cooperation, and that they can be considered as a quality learning media.

\subsubsection{Formative assessment using an application based on AR}

The effectiveness of using formative assessment based on AR to improve achievement and motivation in primary school has been examined by Bhagat, Liou, Spector, and Chang [54]. The results showed that the use of AR-based formative assessment improved not only student learning performance but also their motivation to learn, compared to the traditional formative assessment approach. Stylianidou, Sofianidis, Manoli and Meletiou-Mavrotheris [55] in their paper reported on the main experiences gained from a teaching intervention which utilized the alternate reality game 'Helping Nemo' in an AR environment for formative assessment. The findings suggest that such formative assessment contributes towards higher levels of engagement and participation in learning of all students, including bilingual students, students with learning disabilities, and students who are currently disengaged.

Formative assessment at the higher level of education is explored by Chao, Lan, Kinshuk, Chang and Sung [56]. In their paper they propose a framework that incorporates mobile peer assessment and AR technology to enhance interaction and learning effectiveness. The results showed that the system helped students in acquiring useful information, proposing their viewpoints, and further fostering critical thinking skills and reflection. Similar results that AR-based learning with a formative assessment mechanism significantly improved student achievement and motivation in learning, while reducing their cognitive load, were obtained by Chu, Chen J.-M. Hwang and Chen T.-W. [57]. They proposed an AR system for learning in a university architecture course based on a formative assessment mechanism, by leading students to find answers on their own and giving them hints when they fail to answer questions correctly. 
Although two papers analyze the effectiveness of using formative assessment based on AR in primary education, and the other two in tertiary education, the common conclusion is that the use of such formative assessment affects learning performance and motivation to learn, contributes to engagement and participation in the learning of all students, and helps students in acquiring useful information and further encouragement of critical thinking.

\subsubsection{Interests and attitudes of professors, students and faculty on the use of AR in education}

All analyzed papers are related to higher education. Tebeanu, Chicioreanu, Amza and Macarie [58] in their paper conducted at Higher Education centers in Romania, Malta, Iceland, and Lithuania analyzed the need of students and professors regarding AR in technical disciplines. The results showed that one third of the respondents indicated the use or prior knowledge of AR in the educational environment, and that they are enthusiastic about the future implementation of the activities. Alsadoon and Alhussain [59] examined the possibility of implementing the AR application in higher education in faculties at Saudi Electronic University. They concluded that faculties have a positive attitude towards the use of the AR in the educational environment, but results also showed that there are concerns about some barriers such as the lack of technical support. I. Stojšić et al. [60] in their paper researched the students' attitudes toward the application of mobile AR (MAR), and the results showed that the students have mostly a positive attitude.

Durão, Moreira, Ferreira, Santos-Pereira and Annamalai [61] investigated the perception that higher education professors in the area of technology, across South Europe, South America, and Asia countries have about the use of mobile technologies such as gamification and AR, and how they can be used to promote student's engagement inside and outside of the classroom. The results of the study indicate a similar situation in all countries with small differences in terms of student participation, engagement, and mobile use in the classroom. As a general conclusion, they state that most professors have excellent knowledge of how to perform certain trivial tasks.

The results of all four analyzed papers show the positive attitudes of professors and students about the usage of AR in colleges.

\subsection{Discussion}

Based on the analysis of papers by categories, it is possible to draw several conclusions and also answer the third research question: What common conclusions can be drawn from the synthesis of papers obtained by analysis in each thematic category? In the first thematic category where the papers related to the usage of the AR in education are analyzed, the conclusion is that the number of published papers related to EMARG and ARGBL in primary and secondary education is gradually increasing and also the number of teachers using them. That can be related to positive attitudes of professors and students on the use of the AR in the faculties determined 
in the last thematic category. The conclusion in the first category is also that the AR, and especially with the game elements in general, have a positive effect on students' attitudes, as well as on the learning outcome. This is mostly confirmed in the category in which the analyzed papers confirmed the positive impact of the AR on the effectiveness, motivation and achievement of students with or without the use of game elements in all three levels of education. Regardless of gender, students like that kind of way of learning. The results of effective motivation, but also the higher levels of engagement of all students were found in the category in which an application based on the AR with or without game elements is applied for the purpose of formative assessment. Such engagement through collaboration when playing games promotes motivation, but also increases student involvement and it is recognized in most thematic categories. All analyzed applications show that they all have educational value, have positive characteristics of the game such as current feedback and dynamics of cooperation, and that they can be considered a quality learning media.

Although the negative aspects are mentioned very little, some that are present in certain categories can be singled out. These are possible technical problems of the AR usage, impracticability of certain activities in everyday practice, lack of expertise and time by teachers to design and implement ARGBL applications, and difficulties associated with the use of mobile devices, such as the need for internet connection, slowness and prohibition of mobile devices in schools.

\section{Conclusion}

The aim of this paper was to give a literature review and analyze already researched topics in the field of using AR technology in education in the past 10 years, from 2010 till 2020. But because of the frequent use of game elements with the AR, both aspects were included in the research. The research methodology was carried out following the steps proposed by J. W. Creswell [7]. After the papers relevant to the research topic have been selected, the final result is 52 papers describing various aspects of the usage of augmented reality in the field of education.

Answering the first research question: What thematic categories can be identified in the analyzed papers?, the initial analysis identified five basic categories. Thus we distinguish I) papers that provide an overview of the literature related to the use of AR in education, II) those that deal with its impact on the effectiveness, motivation and achievement of students with or without the game elements, III) those that focus on designing and testing learning applications based on AR and game elements, IV) those that examined the impact of applications based on AR on formative assessment and V) those that consider the interests and attitudes of professors, students and faculties on the use of AR in education. In the category describing the impact of the AR on the effectiveness, motivation and achievement of students with or without game elements, a division was made according to the level of education, where level 1 is primary, level 2 is secondary, and level 3 is tertiary education.

Observing the distribution of selected papers in each thematic category with additional consideration of the year of publication according to paper reference, we can conclude that the number of papers dealing with the AR and game elements in 
education has increased in the last 5 years. From 2010 to 2015, only 10 papers were published, while from 2016 to 2020, 42 papers were published. The largest number of analyzed papers was published in 2019 , which means that the publication of papers has decreased in the last year. This analysis is the answer to the second research question: What is the representation of the papers in a certain thematic category considering the year of publication??

In order to answer the third research question: What common conclusions can be drawn from the synthesis of papers obtained by analysis in each thematic category?, after the analysis of the selected papers, which were grouped according to the established thematic structure, their synthesis followed according to the recognized important concepts on the basis of which several conclusions described in Chapter 3.2 were drawn. However, the main idea that extends through all analyzed papers is that the use of AR in teaching activities, and especially with game elements, improves student efficiency, encourages attention and interest, brings improvements in collaboration and perception of fun, improves teaching and learning processes and generally encourages innovations and improvements through educational technology.

The use of AR in education is a new area that requires further research, especially about formative assessment usage where the positive impact of AR has been identified, but only a few papers dealing with that thematic have been found. Just one of them is using AR with game elements for formative assessment, which indicate insufficient research in this area. Also, detailed research about interest and attitudes of professors and students according to the use of AR in education were found only in papers focused on higher levels of education. Given all of the above, further research should be focused on primary and/or secondary level of education with the above mentioned focus.

\section{References}

[1] I. Mišurac, "Prirucnik_Scenarij-poucavanja.pdf." [Online]. Available: https://pilot.e-skole.hr/wp-content/uploads/2016/12/Prirucnik_Scenarijpoucavanja.pdf. [Accessed: Dec. 5, 2020].

[2] I. Matasić and S. Dumić, "Multimedijske tehnologije u obrazovanju," Medijska Istraživanja Znan.-Stručni Časopis Za Novinarstvo Medije, vol. 18, no. 1, pp. 143-151, Jun. 2012. [Online]. Available: https://hrcak.srce.hr/85389. [Accessed: Dec. 10, 2020.]

[3] L. E. Bruno, "Get Gamified: Promoting Augmented Reality and Digital Game Technology in Education", Springer International Publishing, 2019, pp. 237-251.

[4] M. Kesim and Y. Ozarslan, "Augmented Reality in Education: Current Technologies and the Potential for Education," Procedia - Soc. Behav. Sci., vol. 47, pp. 297-302, 2012, doi: 10.1016/j.sbspro.2012.06.654. 
[5] R. Azuma, Y. Baillot, R. Behringer, S. Feiner, S. Julier, and B. MacIntyre, "Recent advances in augmented reality," IEEE Comput. Graph. Appl., vol. 21, no. 6, pp. 34-47, Nov. 2001, doi: 10.1109/38.963459.

[6] D. P. Vukovac, M. Škara, and G. Hajdin, "Korištenje i stavovi nastavnika o igrifikaciji u osnovnim i srednjim školama," Zbornik Veleučilišta U Rijeci, vol. 6, no. 1, pp. 181-196, 2018, doi: 10.31784/zvr.6.1.14.

[7] J. W. Creswell, Research design: qualitative, quantitative, and mixed methods approaches, 4th ed. Thousand Oaks: SAGE Publications, 2014.

[8] M. Čuljak and L. M. Poplašen, "Usporedba citatnih izvora na uzorku znanstvenika javnozdravstvene institucije u Hrvatskoj : Web of Science Core Collection, Scopus i Google Scholar," Vjesn. Bibl. Hrvat., vol. 62, no. 1, pp. 129-150, Jul. 2019, doi: 10.30754/vbh.62.1.654.

[9] A. Bralić, "Approaches to learning in a blended learning environment: Preliminary results," in 2018 41st International Convention on Information and Communication Technology, Electronics and Microelectronics (MIPRO), May 2018, pp. 0777-0782, doi: 10.23919/MIPRO.2018.8400144.

[10] H. Swensen, "Potential of augmented reality in sciences education. A literature review," Nov. 2016, doi: 10.21125/iceri.2016.1546.

[11] T.-C. Lin and C.-C. Tsai, "Innovative technology for science learning and instruction: Innovative technology-assisted science learning in Taiwan," Sci. Educ. Res. Pract. Taiwan Chall. Oppor., pp. 189-209, Aug. 2016, doi: 10.1007/978-981-287-472-6_10.

[12] T. Laine, "Mobile Educational Augmented Reality Games: A Systematic Literature Review and Two Case Studies," vol. 7, Mar. 2018, doi: 10.3390/computers7010019.

[13] P. Fotaris, N. Pellas, I. Kazanidis, and P. Smith, "A systematic review of Augmented Reality game-based applications in primary education," Oct. 2017.

[14] N. Pellas, P. Fotaris, I. Kazanidis, and D. Wells, “Augmenting the learning experience in primary and secondary school education: a systematic review of recent trends in augmented reality game-based learning," Virtual Real., vol. 23, no. 4, pp. 329-346, Dec. 2019, doi: 10.1007/s10055-018-0347-2.

[15] C.-H. Chen, C.-Y. Huang, and Y.-Y. Chou, "Integrating Augmented Reality into Blended Learning for Elementary Science Course," in Proceedings of the 5th International Conference on Information and Education Technology, New York, NY, USA, Jan. 2017, pp. 68-72, doi: $10.1145 / 3029387.3029417$.

[16] E. Solak i R. Cakır, "Investigating the Role of Augmented Reality Technology in the Language Classroom", Croatian Journal of Education, 
vol.18, no. 4, pp. 1067-1085, 2016. [Online].

https://doi.org/10.15516/cje.v18i4.1729

[17] C.-H. Chen, "AR videos as scaffolding to foster students' learning achievements and motivation in EFL learning," Br. J. Educ. Technol., vol. 51, no. 3, pp. 657-672, Jan. 2020, doi: 10.1111/bjet.12902.

[18] R. Leitão, J. M. F. Rodrigues, and A. F. Marcos, “Game-Based Learning: Augmented Reality in the Teaching of Geometric Solids," International Journal of Art, Culture and Design Technologies (IJACDT), vol. 4, no. 1, pp. 63-75, 2014, doi: 10.4018/ijacdt.2014010105.

[19] J. C. Young, M. B. Kristanda and S. Hansun, "ARmatika: 3D game for arithmetic learning with Augmented Reality technology," 2016 International Conference on Informatics and Computing (ICIC), Mataram, 2016, pp. 355-360, doi: 10.1109/IAC.2016.7905744.

[20] F. A. Pritami and I. Muhimmah, "Digital Game Based Learning using Augmented Reality for Mathematics Learning," in Proceedings of the 2018 7th International Conference on Software and Computer Applications, New York, NY, USA, Feb. 2018, pp. 254-258, doi: $10.1145 / 3185089.3185143$.

[21] S.-Y. Chen, C.-Y. Hung, Y.-C. Chang, Y.-S. Lin, and Y.-H. Lai, "A Study on Integrating Augmented Reality Technology and Game-Based Learning Model to Improve Motivation and Effectiveness of Learning English Vocabulary," Aug. 2018, doi: 10.1109/ic3.2018.00015.

[22] K.-C. Hao and L.-C. Lee, "The development and evaluation of an educational game integrating augmented reality, ARCS model, and types of games for English experiment learning: an analysis of learning," Interact. Learn. Environ., pp. 1-14, May 2019, doi: 10.1080/10494820.2019.1619590.

[23] F. Herpich, F. B. Nunes, J. V. D. Lima, and L. M. R. Tarouco, "Augmented Reality Game in Geography: An Orientation Activity to Elementary Education," in 2018 International Conference on Computational Science and Computational Intelligence (CSCI), Dec. 2018, pp. 601-606, doi: 10.1109/CSCI46756.2018.00121.

[24] J.-M. Sáez-López, M. L. Sevillano-García-García, and M. de los Á. Pascual-Sevillano, "Application of the ubiquitous game with augmented reality in Primary Education," Comunicar, vol. 27, no. 61, pp. 71-82, Oct. 2019, doi: 10.3916/c61-2019-06.

[25] D. Spikol and J. Eliasson, "Lessons from Designing Geometry Learning Activities that Combine Mobile and 3D Tools," 2010 6th IEEE International Conference on Wireless, Mobile, and Ubiquitous 
Technologies in Education, Kaohsiung, 2010, pp. 137-141, doi: 10.1109/WMUTE.2010.44.

[26] S. Cai, X. Wang, and F.-K. Chiang, "A case study of Augmented Reality simulation system application in a chemistry course," Comput. Hum. Behav., vol. 37, pp. 31-40, Aug. 2014, doi: 10.1016/j.chb.2014.04.018.

[27] L. BOONTERNG and N. Srisawasdi, "Monitoring Gender Participation with Augmented Reality represented Chemistry Phenomena and Promoting Critical Thinking," Dec. 2015.

[28] I. KUMTA and N. Srisawasdi, "Investigating Correlation between Students' Attitude toward Chemistry and Perception toward Augmented Reality, and Gender Effect,“ Dec. 2015.

[29] M. SAKULPHON, N. Srisawasdi, and P. Wangsomnuk, "Examining Relationship between Biology Attitudes and Perceptions toward Mobile Augmented Reality of Photosynthesis and Impact on Gender Difference," Dec. 2015.

[30] H. Hou and Y. Lin, "The Development and Evaluation of an Educational Game Integrated with Augmented Reality and Virtual Laboratory for Chemistry Experiment Learning," 2017 6th IIAI International Congress on Advanced Applied Informatics (IIAI-AAI), Hamamatsu, 2017, pp. 10051006, doi: 10.1109/IIAI-AAI.2017.14.

[31] N. Meekaew and W. Ketpichainarong, "An Augmented Reality to Support Mobile Game-Based Learning in Science Museum on Biodiversity," in 2018 7th International Congress on Advanced Applied Informatics (IIAIAAI), Jul. 2018, pp. 250-255, doi: 10.1109/IIAI-AAI.2018.00055.

[32] M. Salazar, J. Gaviria, C. Laorden and P. G. Bringas, "Enhancing cybersecurity learning through an augmented reality-based serious game," 2013 IEEE Global Engineering Education Conference (EDUCON), Berlin, 2013, pp. 602-607, doi: 10.1109/EduCon.2013.6530167.

[33] I.-J. Lee, "Using augmented reality to train students to visualize threedimensional drawings of mortise-tenon joints in furniture carpentry," Interact. Learn. Environ., vol. 28, no. 7, pp. 930-944, Jan. 2019, doi: 10.1080/10494820.2019.1572629.

[34] K.-Y. Chin, C.-S. Wang, and Y.-L. Chen, "Effects of an augmented realitybased mobile system on students' learning achievements and motivation for a liberal arts course," Interact. Learn. Environ., vol. 27, no. 7, pp. 927941, Oct. 2019, doi: 10.1080/10494820.2018.1504308.

[35] D. Richardson, "Exploring the Potential of a Location Based Augmented Reality Game for Language Learning," Int. J. Game-Based Learn., vol. 6, no. 3, pp. 34-49, Jul. 2016, doi: 10.4018/ijgbl.2016070103. 
[36] J. Lee, "Correction to: Problem-based gaming via an augmented reality mobile game and a printed game in foreign language education," Educ. Inf. Technol., Dec. 2020, doi: 10.1007/s10639-020-10409-8.

[37] I. Kazanidis, A. Tsinakos, and C. Lytridis, Teaching Mobile Programming Using Augmented Reality and Collaborative Game Based Learning. 2018. pp. $850-859$.

[38] V. Ferrer, A. Perdomo, H. Rashed-Ali, C. Fies and J. Quarles, "How Does Usability Impact Motivation in Augmented Reality Serious Games for Education?," 2013 5th International Conference on Games and Virtual Worlds for Serious Applications (VS-GAMES), Poole, 2013, pp. 1-8, doi: 10.1109/VS-GAMES.2013.6624233.

[39] V. Ferrer, A. Perdomo, H. R. Ali, C. Fies, and J. Quarles, "Virtual humans for temperature visualization in a tangible augmented reality educational game," in 2017 IEEE Virtual Reality Workshop on K-12 Embodied Learning through Virtual Augmented Reality (KELVAR), Mar. 2017, pp. 1-6, doi: 10.1109/KELVAR.2017.7961559.

[40] I. Alakärppä, E. Jaakkola, J. Väyrynen, and J. Häkkilä, “Using nature elements in mobile AR for education with children," in Proceedings of the 19th International Conference on Human-Computer Interaction with Mobile Devices and Services, New York, NY, USA, Sep. 2017, pp. 1-13, doi: $10.1145 / 3098279.3098547$.

[41] L. Ştefan and F. Moldoveanu,“'Game-based Learning with Augmented Reality - From Technology's Affordances to Game Design and Educational Scenarios“. Apr. 2013.

[42] H. Tobar, R. Fabregat, and S. Baldiris, Method for the Co Design of Augmented Reality Game-Based Learning Games with Teachers. Aug. 2016.

[43] H. Tobar, S. Baldiris, and R. Fabregat, "Augmented Reality Game-Based Learning: Enriching Students' Experience During Reading Comprehension Activities," J. Educ. Comput. Res., vol. 55, p. 073563311668978 , Feb. 2017, doi: 10.1177/0735633116689789.

[44] E. Sudarmilah, N. Ustia, and D. Bakhtiar,"Learning Media based on Augmented Reality Game“, vol. 8. pp. 154-157, Jan. 2019, doi: 10.14419/ijet.v8i1.1.24653.

[45] M. C. Costa, A. Manso, and J. Patrício, "Design of a Mobile Augmented Reality Platform with Game-Based Learning Purposes," Information, vol. 11, no. 3, p. 127, Feb. 2020, doi: 10.3390/info11030127.

[46] P. Mozelius, S. Eriksson Bergström, and J. Jaldemark, 'Learning by Walking - Pokémon Go and Mobile Technology in Formal Education', in ICERI2017 Proceedings, 2017, vol. 10, pp. 1172-1179., Nov. 2017. 
[47] L. Pombo, M. Marques, M. Lucas, V. Carlos, M. J. Loureiro, and C. Guerra, "Moving learning into a smart urban park: students' perceptions of the Augmented Reality EduPARK mobile game," IxD\&A, N.35, pp. 117$134,2017$.

[48] L. Pombo and M. M. Marques, "Learning with the Augmented Reality EduPARK Game-Like App: Its Usability and Educational Value for Primary Education," in Intelligent Computing, Cham, 2019, pp. 113-125, doi: 10.1007/978-3-030-22871-2_9.

[49] L. Pombo and M. M. Marques, "Improving students' learning with a mobile augmented reality approach - the EduPARK game," Interact. Technol. Smart Educ., vol. 16, no. 4, pp. 392-406, Nov. 2019, doi: 10.1108/itse-06-2019-0032.

[50] A. Ortiz, C. Vitery, C. González, and H. Tobar-Muñoz, "Evaluation of an Augmented Reality Multiplayer Learning Game," in Serious Games, Cham, 2018, pp. 91-100, doi: 10.1007/978-3-030-02762-9_10.

[51] G.-J. Hwang, P.-H. Wu, C.-C. Chen, and N.-T. Tu, "Effects of an augmented reality-based educational game on students' learning achievements and attitudes in real-world observations," Interact. Learn. Environ., vol. 24, no. 8, pp. 1895-1906, Nov. 2016, doi: 10.1080/10494820.2015.1057747.

[52] L. López-Faican and J. Jaen, "EmoFindAR: Evaluation of a mobile multiplayer augmented reality game for primary school children," Comput. Educ., vol. 149, p. 103814, May 2020, doi: 10.1016/j.compedu.2020.103814.

[53] D. M. Bressler, A. M. Bodzin, and M. S. Tutwiler, "Engaging middle school students in scientific practice with a collaborative mobile game," J. Comput. Assist. Learn., vol. 35, no. 2, pp. 197-207, 2019, doi: https://doi.org/10.1111/jcal.12321.

[54] K. K. Bhagat, W.-K. Liou, J. M. Spector, and C.-Y. Chang, "To use augmented reality or not in formative assessment: a comparative study," Interact. Learn. Environ., vol. 27, no. 5-6, pp. 830-840, Jun. 2018, doi: 10.1080/10494820.2018.1489857.

[55] N. Stylianidou, A. Sofianidis, E. Manoli, and M. Meletiou-Mavrotheris, “'Helping Nemo!'-Using Augmented Reality and Alternate Reality Games in the Context of Universal Design for Learning," Educ. Sci., vol. 10, no. 4, p. 95, Apr. 2020, doi: 10.3390/educsci10040095.

[56] K.-H. Chao, C.-H. Lan, D. Kinshuk, K. Chang, and Y.-T. Sung, "Implementation of a mobile peer assessment system with augmented reality in a fundamental design course," Knowl. Manag. E-Learn. Int. J., vol. 6, pp. 123-139, 2014. 
[57] H.-C. Chu, J.-M. Chen, G.-J. Hwang, and T.-W. Chen, "Effects of formative assessment in an augmented reality approach to conducting ubiquitous learning activities for architecture courses," Univers. Access Inf. Soc., vol. 18, no. 2, pp. 221-230, Jun. 2019, doi: 10.1007/s10209-0170588-y.

[58] A. V. Tebeanu, T. D. Chicioreanu, C. G. Amza, and G. F. Macarie, “A MULTICENTER STUDY ON AUGMENTED REALITY IN TECHNICAL EDUCATION: KNOWLEDGE AND INTEREST," INTED2017 Proc., pp. 7638-7642, 2017.

[59] H. Alsadoon and T. Alhussain, "Faculty at Saudi Electronic University attitudes toward using augmented reality in education," Educ. Inf. Technol., vol. 24, no. 3, pp. 1961-1972, May 2019, doi: 10.1007/s10639018-9826-z.

[60] I. Stojšić, A. Ivkov-Džigurski, O. Maričić, J. Stanisavljević, J. Milanković Jovanov, and T. Višnić, "Students' Attitudes toward the Application of Mobile Augmented Reality in Higher Education", Društvena istraživanja, vol.29, no. 4, pp. 535-554, Nov. 2020, doi: 10.5559/di.29.4.02.

[61] N. Durão, F. Moreira, M. J. Ferreira, C. S. Pereira and N. Annamalai, "A comparative study about mobile learning with gamification and augmented reality in high education institutions across South Europe, South America, and Asia countries," 2019 14th Iberian Conference on Information Systems and Technologies (CISTI), Coimbra, Portugal, 2019, pp. 1-6, doi: 10.23919/CISTI.2019.8760854. 